\title{
Analytical study of thyroid and prolactin hormone levels in infertile women with menstrual irregularities
}

\author{
S. R. Keerthanaa ${ }^{1}$, P. B. Hiremath ${ }^{2 *}$
}

\author{
${ }^{1}$ Department of Obstetrics and Gynecology, Sri Venkateshwaraa Medical College, Ariyur, Puducherry, India \\ ${ }^{2}$ Department of Obstetrics and Gynecology, Sri Venkateshwaraa Medical College Hospital and Research Centre, \\ Ariyur, Puducherry, India
}

Received: 08 February 2020

Accepted: 28 February 2020

*Correspondence:

Dr. P. B. Hiremath,

E-mail: srkeerthanaa1992@gmail.com

Copyright: (C) the author(s), publisher and licensee Medip Academy. This is an open-access article distributed under the terms of the Creative Commons Attribution Non-Commercial License, which permits unrestricted non-commercial use, distribution, and reproduction in any medium, provided the original work is properly cited.

\begin{abstract}
Background: Infertility is the inability of a couple to achieve pregnancy over an average period of one year (in a woman under 35 years of age) or 6 months (in a woman above 35 years of age) despite adequate, regular (3-4 times per week), unprotected sexual intercourse. It is of two types, primary infertility and secondary infertility. It can be due to the woman, the man, or both men and woman. Though there are several factors plays role in the causing infertility, endocrine hormones play a crucial role in it. Among all the hormones, thyroid and prolactin hormone have profound effects on reproduction and pregnancy.

Methods: A prospective analytical study was conducted among 200 female patients, of age group 20-40 years, attending the outpatient department of obstetrics and gynecology. Sent for analysis of thyroid profile and prolactin levels. The data of the patients who have been completely followed up after six months was entered in excel sheet and analyzed using SPSS (version 16).

Results: In this study the mean age of the study participants were $31.33 \pm 4.12$ years and 4 of them were below 25 years of age. There is high prevalence of hypothyroidism (23.5\%) and hyperprolactinemia (31\%) was noted among the infertile females.

Conclusions: The assessment of thyroid function and prolactin levels is mandatory in the work up of all infertile women, especially those presenting with menstrual irregularities. Also, early initiation of treatment may help in restoring the fertility among the infertile woman.
\end{abstract}

Keywords: Hyperprolactinemia, Infertility, Pregnancy, Thyroid disorders

\section{INTRODUCTION}

Infertility is the inability of a couple to achieve pregnancy over an average period of one year (in a woman under 35 years of age) or 6 months (in a woman above 35 years of age) despite adequate, regular (3-4 times per week), unprotected sexual intercourse. ${ }^{1}$ Infertility can be due to the woman, the man, or both men and woman. Infertility is of two types, primary infertility and secondary infertility. In primary infertility, the couples have never been able to conceive whereas in cases of secondary infertility there is difficulty in conceiving after having conceived that is either carried the pregnancy to term or had a miscarriage.

Though there are several factors plays role in the causing infertility, endocrine hormones play a crucial role in it. Among all the hormones, thyroid hormones have profound effects on reproduction and pregnancy. There are several experimental evidences, conducted both in animals and also in humans which proved that there is association of hyperthyroidism or hypothyroidism with 
menstrual disturbance, anovulatory cycles, decreased fecundity and increased morbidity during pregnancy., Most importantly proper management of such thyroid dysfunction results in improvement in health status, normalization of menstrual abnormalities and restoration of normal fertility. ${ }^{4}$ Therefore it is very important to screen thyroid abnormalities among women with infertility, particularly in countries like India, considered as areas with endemic goiter. Infertility associated with thyroid dysfunction in these areas is not uncommon. ${ }^{5}$

Secondly prolactin, a hormone which is secreted by the anterior pituitary lactotroph, is the primary trophic factor responsible for synthesis of milk by the breast. ${ }^{6}$ Increased secretion of prolactin hormone secretion is a condition called as hyperprolactinaemia.

Hyperprolactinemia is also one of the common problems which is encountered in reproductive disorder. ${ }^{7}$ Hyperprolactinemia and hypothyroidism are found to be closely inter-related. Ovulation can be affected by hormonal imbalance, thyroid disorders or chronic diseases such as diabetes. ${ }^{8}$ Some women with galactorrhea and hyperprolactinemia might have primary hypothyroidism, which is characterized by low serum levels of thyroxine (T4) and decreased negative feedback on the hypothalaopituitary axis. The resulting increased secretion of thyrotropin releasing hormone (TRH) stimulates thyrotropes and lactotrophs, thereby increasing the levels of both TSH and prolactin. ${ }^{9}$ Primary hypothyroidism is commonly associated with hyperprolactinemia due to the stimulatory effect of TRH on lactotrophs. ${ }^{10}$ Women with hyperprolactinemia are often associated with hypothyroidism which is characterized by high serum TSH levels. ${ }^{7}$

Hyperprolactinemia which results from a longstanding primary hypothyroidism may result in ovulatory dysfunctions ranging from inadequate corpus luteal progesterone secretion to oligomenorrhoea or ammenorhoea. ${ }^{11}$ Amenorrhoea occurs in hypothyroidism due to hyperprolactinaemia, which results from a defect in the positive feedback of oestrogen on $\mathrm{LH}$, and because of the suppression of LH and FSH. ${ }^{12}$

Thyroid dysfunction is implicated in a broad spectrum of reproductive disorders, ranging from abnormal sexual development to menstrual irregularities and infertility. ${ }^{13}$ Hypothyroidism is associated with increased production of TRH, which stimulates pituitary to secrete TSH and prolactin. Hyperprolactinemia adversely affects the fertility potential by impairing pulsatile secretion of $\mathrm{GnRH}$ and hence interfering with ovulation. ${ }^{14}$

Even in the absence of hyperprolactinaemia, hypothyroidism may itself contribute to infertility. ${ }^{15}$ Thus measurements of prolactin and thyroid hormones especially thyroid stimulating hormone (TSH) has been considered an important component of Infertility work up in women. ${ }^{16}$ Hence this study was conducted to assess the present prevalence of thyroid and prolactin disorders among the patients with infertility.

Aims and objective of this study were to analyse the role of thyroid and prolactin hormone level in infertile women with menstrual irregularities. To analyse the role of thyroid and prolactin hormone level in infertile women with menstrual irregularities and the response of treatment for hypothyroidism and hyperprolactinemia on infertility.

\section{METHODS}

This prospective analytical study conducted during the period of November 2017 to May 2019. This was done to assess the role of thyroid and prolactin hormone level in infertile women with menstrual irregularities and the response of treatment for hypothyroidism and hyperprolactinemia on infertility. This study was conducted in the department of obstetrics and gynecology in Sri Venkateshwaraa Medical college Hospital and Research Centre, a tertiary care teaching hospital located in Ariyur, Pondicherry, India.

Patients attending the outpatient department of obstetrics and gynecology with the complaints of infertility during the study period were included in the study.

\section{Inclusion criteria}

- Women between the age group of 20-40 years were included in this study.

\section{Exclusion criteria}

- Women below 20 years of age and above 40 years of age

- Male factor infertility

- Female factors like tubal factors, endometriosis and

- Women with any congenital anomaly of urogenital tract, were excluded from the study.

A total of 200 women, between $20-40$ years of age with complaints of infertility who presented to obstetrics and gynecological outpatient department were included in this study.

Ethical committee approval was obtained for this study, to assess the role of thyroid and prolactin hormone level in infertile women with menstrual irregularities and the response of treatment for hypothyroidism and hyperprolactinemia on infertility from the institutional Human ethics committee in Sri Venkateshwaraa Medical college Hospital and Research centre, Puducherry, India.

Patients presenting to outpatient department of obstetrics and gynecology with complaints of infertility between the months of November 2017 to May 2019 were included in the study. The individual participants were explained about the study and they were also assured that, their 
identity would be kept strictly confidential and they have the option to refuse participation in the study.

Written informed consent was obtained from the study participant prior to the interview. Both the English and Tamil formats of the Informed consent are enclosed in Annexure III and Annexure IV, respectively.

After assessing the inclusion and exclusion criteria, written informed consent was taken from the study participants. Using a proforma, (Annexure V) the principal investigator conducted one to one interview with the patient and their responses were noted. Following which $2 \mathrm{ml}$ of venous blood was collected from each participant and the sent for analysis of thyroid profile and prolactin levels. Also, the reports of these investigations were entered in the same proforma.

Based on the report's patients were started on treatment for the correction of thyroid and prolactin disorders. Thyroxine 25-150 $\mu$ g (Thyrox, Thyronorm, Eltroxin) was given to hypothyroid infertile females depending upon TSH levels. Carbergoline was given in case of hyperprolactinemia. Also, the patients were contacted after six months and their conception status were assessed.

\section{Statistical analysis}

Only the observations from the patients who have been completely followed up after six months were taken up for statistical analysis. The data was entered in excel sheet and analyzed using SPSS (version 16).

Descriptive statistics with mean, standard deviation and proportion (\%) were calculated for quantitative variables. To test the hypothesis Chi Square test and Independent sample t-test was used. $\mathrm{p}$ value $<0.05$ was considered as statistically significant.

\section{Operational definitions}

- Thyroid stimulating hormone (TSH) measured by the electrochemiluminescence method. Normal TSH was considered as $0.27-4.2 \mu \mathrm{IU} / \mathrm{ml}$ as per kit supplier's instruction. Therefore, hypothyroidism was considered at TSH levels of $>4.2 \mu \mathrm{IU} / \mathrm{ml}$

- Prolactin level was also measured by the electrochemiluminescence method. Normal PRL level was considered as $1.9-25 \mathrm{ng} / \mathrm{ml}$, as per kit supplier's instruction. Therefore, hyperprolactinemia at PRL levels of $>25 \mathrm{ng} / \mathrm{ml}$.

\section{RESULTS}

In this study among 200 participants 4 of them were below 25 years of age. In the age group of 26-30 years there were 63 participants and in the age range of 31-35 years 85 participants were in this study. In the age group of 35-40 years 48 participants were recorded. The mean age of the study participants was $31.33 \pm 4.12$ years.

Table 1: Age group of the participants.

\begin{tabular}{|l|ll|}
\hline Age group & Frequency & Percentage \\
\hline$\leq 25$ years & 4 & $2 \%$ \\
\hline 26-30 years & 63 & $31.5 \%$ \\
\hline $31-35$ years & 85 & $42.5 \%$ \\
\hline 35-40 years & 48 & $24 \%$ \\
\hline Total & $\mathbf{2 0 0}$ & $\mathbf{1 0 0} \%$ \\
\hline
\end{tabular}

Among all the participants $169(84.5 \%)$ of the participants were housewives and $31(15.5 \%)$ participants were employed.

In this study among 200 participants, 109 (54.5\%) of them were found to be overweight and $34(17 \%)$ of them were obese. Normal BMI was recorded among 57 (28.5\%) study participants. The mean BMI was found to be $26.2 \pm 3.61 \mathrm{~kg} / \mathrm{m}^{2}$.

Table 2: BMI group of the participants.

\begin{tabular}{|l|l|l|}
\hline BMI & Frequency & Percentage \\
\hline Normal & 57 & $28.5 \%$ \\
\hline Overweight & 109 & $54.5 \%$ \\
\hline Obese & 34 & $17 \%$ \\
\hline Total & $\mathbf{2 0 0}$ & $\mathbf{1 0 0} \%$ \\
\hline
\end{tabular}

Menstrual irregularities like oligohydramnios, menorrhagia and amenorrhoea was found in $65.5 \%$, $22.5 \%$ and $12 \%$ of the participants respectively.

Table 3: Menstrual irregularities of the participants.

\begin{tabular}{|ll|l|}
\hline Menstrual irregularities & Frequency & Percentage \\
\hline Oligohydromnias & 131 & $65.5 \%$ \\
\hline Amenorrhoea & 24 & $12 \%$ \\
\hline Menorrhagia & 45 & $22.5 \%$ \\
\hline Total & $\mathbf{2 0 0}$ & $\mathbf{1 0 0} \%$ \\
\hline
\end{tabular}

In this study regarding infertility, the duration of infertility was found to be more than 6 years for 35 (17.5\%) participants, between 4-6 years for $103(51.5 \%)$ of the participants and $1-3$ years for 62 (31\%) participants.

Table 4: Participants' duration of infertility.

\begin{tabular}{|lll|}
\hline Duration of infertility & Frequency & Percentage \\
\hline $1-3$ years & 62 & 31 \\
\hline 4-6 years & 103 & 51.5 \\
\hline$>$ 6 years & 35 & 17.5 \\
\hline Total & $\mathbf{2 0 0}$ & $\mathbf{1 0 0}$ \\
\hline
\end{tabular}

Among 200 infertility participants the cause of infertility was ovulatory among $76(38 \%)$ of them, tubal factors in 
$57(28.5 \%)$ of the participants, unexplained cause among $53(26.5 \%)$ participants and in $14(7 \%)$ participants endometriosis is the cause for infertility.

Table 5: Causes of infertility among participants.

\begin{tabular}{|lll|}
\hline Causes of infertility & Frequency & Percentage \\
\hline Tubal factors & 57 & $28.5 \%$ \\
\hline Ovulatory & 76 & $38 \%$ \\
\hline Endometriosis & 14 & $7 \%$ \\
\hline Unexplained & 53 & $26.5 \%$ \\
\hline Total & $\mathbf{2 0 0}$ & $\mathbf{1 0 0 \%}$ \\
\hline
\end{tabular}

Among 200 participants 38 participants were found to be hypothyroid, out of them 24 presented with symptoms of fatigue, 17 had alopecia, 11 presented with cold intolerance, 6 of them had dry skin, 3 participants presented with muscle cramps and 2 had hirsutism.

Table 6: Participants with hypothyroid features.

\begin{tabular}{|l|l|l|}
\hline Hypothyroid features & Frequency & Percentage \\
\hline Present & 38 & $19 \%$ \\
\hline Absent & 162 & $81 \%$ \\
\hline Features of hypothyroidism & \\
\hline Fatigue & 24 & $11 \%$ \\
\hline Dry skin & 06 & $3 \%$ \\
\hline Cold intolerance & 11 & $5.5 \%$ \\
\hline Alopecia & 17 & $8.5 \%$ \\
\hline Hirsutism & 02 & $1 \%$ \\
\hline Muscle cramps & 03 & $1.5 \%$ \\
\hline
\end{tabular}

The mean and standard deviation of thyroid profile among 38 participants with hypothyroidism was found to be $2.76 \pm 1.89$ for FT3, $1.81 \pm 0.77$ for FT4, the mean and
SD for TSH was found to be $4.34 \pm 2.16$ and the mean for prolactin was $31.25 \pm 22.45$.

Table 7: Mean and standard deviation of thyroid profile of the study participants.

\begin{tabular}{|l|l|}
\hline Variables & Mean \pm SD \\
\hline FT3 & $2.76 \pm 1.89$ \\
\hline FT4 & $1.81 \pm 0.77$ \\
\hline TSH & $4.34 \pm 2.16$ \\
\hline Prolactin & $31.25 \pm 22.45$ \\
\hline
\end{tabular}

Table 8: Thyroid profile of the study participants.

\begin{tabular}{|c|c|c|}
\hline Thyroid & Frequency & Percentage \\
\hline Euthyroid & 149 & $74.5 \%$ \\
\hline Hypothyroidism & 47 & $23.5 \%$ \\
\hline Hyperthyroidism & 4 & $2 \%$ \\
\hline Total & 200 & $100 \%$ \\
\hline
\end{tabular}

Among 200 participants, 149 were found to have normal thyroid levels, 47 participants were found to be hypothyroidism and 4 participants were found to have hyperthyroidism. Prolactin level was found to be normal in 138 participants and hyperprolactinemia was noted in 62 study participants.

Table 9: Proportion of participants with prolactin status.

\begin{tabular}{|l|ll|}
\hline Prolactin & Frequency & Percentage \\
\hline Normal & 138 & $69 \%$ \\
\hline Hyperprolactinemia & 62 & $31 \%$ \\
\hline Total & $\mathbf{2 0 0}$ & $\mathbf{1 0 0 \%}$ \\
\hline
\end{tabular}

Table 10: Association between prolactin profile and menstrual irregularities.

\begin{tabular}{|c|c|c|c|}
\hline \multirow{2}{*}{ Menstrual irregularities } & \multicolumn{2}{|c|}{ Prolactin profile } & \multirow{2}{*}{ p value } \\
\hline & Normal & Hyperprolactinemia & \\
\hline Oligohydramnios & $97(48.5 \%)$ & $34(17 \%)$ & \multirow{3}{*}{0.082} \\
\hline Amenorrhoea & $13(6.5 \%)$ & $11(5.5 \%)$ & \\
\hline Menorrhagia & $28(14 \%)$ & $17(8.5 \%)$ & \\
\hline
\end{tabular}

Table 11: Association between prolactin profile with duration and causes of infertility.

\begin{tabular}{|lll|}
\hline Variables & $\begin{array}{l}\text { Prolactin profile } \\
\text { Normal }\end{array}$ & Hyperprolactinemia \\
\hline Duration of infertility & & \\
\hline $1-3$ years & $44(22 \%)$ & $18(9 \%)$ \\
\hline 4-6 years & $71(35.5 \%)$ & $32(16 \%)$ \\
\hline$>6$ years & $23(11.5 \%)$ & $12(6 \%)$ \\
\hline Causes of infertility & & \\
\hline Tubal factors & $41(20.5 \%)$ & $16(8 \%)$ \\
\hline Ovulatory & $47(23.5 \%)$ & $29(14.5 \%)$ \\
\hline Endometriosis & $10(5 \%)$ & $04(2 \%)$ \\
\hline Unexplained & $40(20 \%)$ & $13(6.5 \%)$ \\
\hline
\end{tabular}


Likewise, the difference between menstrual irregularities and prolactin profile in this study was not statistically significant ( $\mathrm{p}$ value 0.082 ).

In this study the difference between the duration of infertility and prolactin profile was found to be statistically insignificant, and the difference between causes of infertility and the prolactin profile was also found to be statistically not significant.

\section{DISCUSSION}

This study was conducted to assess the imbalance in thyroid and prolactin hormones which usually presents as hypothyroidism, hyperthyroidism and hyperprolactinemia in infer time woman.

In this study among 200 participants 4 of them were below 25 years of age. In the age group of 26-30 years there were 63 participants and in the age range of 31-35 years 85 participants were in this study. In the age group of 35-40 years 48 participants were recorded.

In this study the mean age of the study participants was $31.33 \pm 4.12$ years. Whereas Nambiar et al conducted a study before and decade and reported the mean age of the subjects were $25.19 \pm 4.17$ years which are lower than the current study. ${ }^{1}$

Among all the participants $169(84.5 \%)$ of the participants were housewives and 31 (15.5\%) participants were employed.

In this study maximum number of participants, 88 of them belonged to class 2 socio economic status, followed by 51 participants in class 3,32 participants in class 1 socioeconomic status. In class 4, there were 23 participants from this study and 6 participants belonged to socioeconomic class 5 .

In this study among 200 participants, $109(54.5 \%)$ of them were found to be overweight and 34 (17\%) of them were obese. Normal BMI was recorded among 57 (28.5\%) study participants. Thyroid profile with BMI of the participants was found to be statistically significant with a $p$ value of 0.0228 , which means there is difference between the thyroid status and body mass index of the patients. Also, there was statistically high significance found between body mass index and prolactin level ( $p$ value 0.000 ).

In the present study the mean BMI were $26.2 \pm 3.61 \mathrm{~kg} /$ $\mathrm{m}^{2}$. Mbah et al, reported statistically significant differences in body weight as found between the hypothyroid and non-hypothyroid pregnant women. ${ }^{2,15}$ The relationship of thyroid function and BMI was described by Glinoer et al and Vermiglio et al. ${ }^{3,4}$

Age of menarche was less than 12 years among $26(13 \%)$ participants, whereas the age of menarche was $12-13$ years in 97 (48.5\%) participants. For 65 (32.5\%) participants in this study the age of menarche was between 14-15 years and the age of menarche was more than 15 years for $12(6 \%)$ participants.

Menstrual irregularities like oligohydramnios, menorrhagia and amenorrhea was found in $65.5 \%, 22.5 \%$ and $12 \%$ of the participants respectively. The difference between thyroid profile and menstrual irregularities among the study participants was found to be highly statistically significant with $p$ value of $<0.0001$. Whereas the difference between menstrual irregularities and prolactin profile in this study was not statistically significant ( $\mathrm{p}$ value 0.082 ).

In this study regarding infertility, the duration of infertility was found to be more than 6 years for 35 (17.5\%) participants, between 4-6 years for $103(51.5 \%)$ of the participants and 1-3 years for 62 (31\%) participants. The difference in the duration of infertility and the thyroid status among the study participants was found to be statistically significant ( $\mathrm{p}$ value 0.001 ) whereas the difference between causes of infertility and the thyroid status was found to be not statistically significant ( $p$ value 0.089 ).

In this study the difference between the duration of infertility and prolactin profile was found to be statistically insignificant, and the difference between causes of infertility and the prolactin profile was also found to be statistically not significant.

Maximum percentage of menstrual abnormality presented by the infertile group was oligomenorrhea whereas Kumkum depicted the state to be smaller (50\%). In the study done by Krasses et al, the prevalence of menstrual irregularities (mainly oligomenorrhea) reached 23\% among hypothyroid patients and they reported significant association between the severity of menstrual abnormalities and higher serum TSH concentrations. ${ }^{5}$

Binita et al reported irregular menstrual cycles, mainly amenorrhea, in $31 \%$ of the cases with hypothyroidism. ${ }^{6}$ This study also revealed an association between menstrual irregularities with raised serum prolactin levels rather than TSH concentrations. A higher incidence of amenorrhea could be linked to hyperprolactinemia that was seen in the majority of patients with hypothyroidism.

In this study, among 200 infertility participants the cause of infertility was ovulatory among $76(38 \%)$ of them, tubal factors in $57(28.5 \%)$ of the participants, unexplained cause among $53(26.5 \%)$ participants and in $14(7 \%)$ participants endometriosis is the cause for infertility.

Among 200 participants 38 participants were found to be hypothyroid, out of them 24 presented with symptoms of fatigue, 17 had alopecia, 11 presented with cold 
intolerance, 6 of them had dry skin, 3 participants presented with muscle cramps and 2 had hirsutism.

The mean and standard deviation of thyroid profile among 38 participants with hypothyroidism was found to be $2.76 \pm 1.89$ for FT3, $1.81 \pm 0.77$ for FT4, the mean and SD for TSH was found to be $4.34 \pm 2.16$ and the mean for prolactin was $31.25 \pm 22.45$.

Among 200 participants, 149 were found to have normal thyroid levels, 47 participants were found to be hypothyroidism and 4 participants were found to have hyperthyroidism.

Significant increase in serum TSH was found among infertile female patients. Majority of the infertile women had serum TSH within normal range, which is in concordance with study of Binita et al. ${ }^{6}$ Prevalence of Hypothyroidism in the reproductive age ranges from 2$4 \%{ }^{7}$

In the study conducted by Bhargav et al study, the prevalence of hypothyroidism was reported as $17.5 \%$ among the infertile females whereas Manjusha et al found to be $20 \%{ }^{8,9}$ Binita et al found the prevalence to be $8 \%$ while Sharma et al found the prevalence to be $20 \%$.

The prevalence of thyroid dysfunction in infertile women was found to be $33.3 \%$ in a study by Rahman et al and $23 \%$ by Sharma et al. ${ }^{11,12}$ In this study, thyroid dysfunction was present in $25.5 \%$ of the infertile women, where $23.5 \%$ had hypothyroidism and $2 \%$ had hyperthyroidism. It is obvious from the observation that fertility of female reproductive system is hampered by altered thyroid hormone levels. Majority of the patients were in euthyroid state which may be due to other cause of infertility.

Hyperthyroidism was found in $2 \%$ of the infertile patients in the present study. Joshi et al, evaluated 53 hyperthyroid patients and found $5.8 \%$ of them to be infertile. ${ }^{13}$ In contrast to hypothyroidism, most women with hyperthyroidism do not have fertility problems, although $25 \%$ may have irregular menses. ${ }^{14}$

Joshi et al, found menstrual irregularities in $65 \%$ of hyperthyroid women compared to $17 \%$ in healthy controls. ${ }^{13}$ Krasses et al, indicated that menstrual disturbances in thyrotoxicosis are 2.5 times more frequent than in the general population. ${ }^{5}$ Hyperprolactinemia resulting from longstanding primary hypothyroidism has been implicated in ovulatory dysfunctions ranging from inadequate corpus luteal progesterone secretion when mildly elevated to oligomenorrhea or amenorrhea when circulating prolactin levels are high. ${ }^{5}$

Amenorrhea occurs in hypothyroidism due to hyperprolactinemia resulting from a defect in the positive feedback of estrogen on LH, and because of LH and FSH suppression. Binita et al study revealed a significant association between abnormal menstrual patterns, as well as anovulatory cycles, with hyperprolactinemia in the infertile group $(\mathrm{p}<0.001){ }^{6}$

In this study, prolactin level was found to be normal in $69 \%$ of participants and hyperprolactinemia was noted in $31 \%$ of study participants.

Hyperprolactinemia also adversely affects the fertility potential by impairing pulsatile secretion of GnRH and hence interfering with ovulation. ${ }^{15}$ In this study, though majority of the infertile women had serum prolactin within normal range, which is concordance with study done by Binita et al, there was a significant increase in serum prolactin (hyperprolactinemia) of infertile female patients $(31 \%){ }^{6}$ This higher propensity of hyperprolactinemia is in agreement with the findings of Kumkum et al who had depicted a prevalence of $46 \%$ in their study. ${ }^{9}$ A study conducted by Sharma $\mathrm{P}$ et al found the occurrence of hyperprolactinemia with a prevalence of $59.37 \%$ while Manjusha et al found it to be $51 \%$. $^{9,10}$ This altered prolactin levels may contribute to the failure of conception and pregnancy as prolactin is supposed to be important for the maintenance of secretory activity of the corpus luteum. ${ }^{15}$

Prolactin inhibits two hormones which are necessary for ovulation: the follicle stimulating hormone (FSH) and the gonadotropin releasing gormone $(\mathrm{GnRH})$. When there are high levels of prolactin in the blood (hyperprolactinaemia), one will not ovulate and this will result in infertility. This anovulation can also cause irregular menstrual cycles. ${ }^{9}$ When the GnRH secretion is low, the FSH and LH secretions are also low and so they do not stimulate the gamete production and the gonadal steroid synthesis. ${ }^{16,17}$

After treatment for 6 months of infertility among 114 participants $86(75.44 \%)$ of them conceived. The mean TSH value among treated participants who conceived was $4.39 \pm 2.55$ but the $\mathrm{p}$ value was found to be not statistically significant ( $\mathrm{p}$ value 0.5594 ). Prolactin mean value among participants who conceived was $28.15 \pm 17.83$, where the difference between participants who conceived and not conceived after treatment was found to be not statistically significant ( $\mathrm{p}$ value 0.2585 ).

Early detection and treatment of hypothyroidism of any degree with low-dose levothyroxine, as a part of combined infertility therapy and during pregnancy, has been recommended. ${ }^{18,19}$ Restoration of prolactin hypersecretion, improvement of luteal-phase function and increase in conception rates in women with otherwise unexplained infertility have been demonstrated after treatment. $^{20,21}$

\section{CONCLUSION}

In the present study there is high prevalence of hypothyroidism and hyperprolactinemia was noted 
among the infertile females. Thyroid dysfunction was found to be significantly associated with BMI, menstrual irregularities and duration of infertility. Similarly, prolactin disorders were found to be associated with BMI alone.

Among the patients treated for hyperprolactinemia and thyroid disorders $24.56 \%$ of them were reported to be pregnant (fertile). Hence, assessment of thyroid function and prolactin levels is mandatory in the work up of all infertile women, especially those presenting with menstrual irregularities. Also, early initiation of treatment may help in restoring the fertility among the infertile woman.

Funding: No funding sources Conflict of interest: None declared

Ethical approval: The study was approved by the Institutional Ethics Committee

\section{REFERENCES}

1. Nambiar V, Jagtap VS, Sarathi V, Lila AR, Kamalanathan S, Bandgar TR, et al. Prevalence and impact of thyroid disorders on maternal outcome in asian-indian pregnant women. J Thyroid Res. 2011; Article ID 429097:1-6.

2. Mbah AU, Ejim EC, Onodugo OD, Ezugwu FO, Eze MI, Nkwo PO, et al. Two logistic models for the prediction of hypothyroidism in pregnancy. BMC Res Notes. 2011;4(205):1-10.

3. Glinoer D, De Nayer P, Bourdoux P, Lemone M, Robyn C, Van Steirteghem A, et al. Regulation of maternal thyroid during pregnancy. J Elin Endocrinol Metab. 1990;71:276-87.

4. Vermiglio F, Lo Presti VP, Scaffidi, Argentina G, Finocchiaro MD, Gullo D, et al. Maternal hypothyroxinaemia during the first half of gestation in an iodine deficient area with endemic cretinism and related disorders. Clin Endocrinol Oxf. 1995;42:409-5.

5. Krassas GE, Pontikides N, Kaltsas T, Papadopoulou P, Paunkovic J, Paunkovic N, et al. Disturbances of menstruation in hypothyroidism. Clin Endocrinol. 1999;50(5):655-9.

6. Goswami B, Patel S, Chatterjee M, Koner BC, Saxena A. Correlation of prolactin and thyroid hormone concentration with menstrual patterns in infertile women. J Reprod Infertil. 2009;10(3):207.

7. Hornstein MD, Davis OK, Massey JB. Antiphospholipid antibodies and in vitro fertilization success: a meta-analysis. Fertil Steril. 2000;73:3303.

8. Mili B, Lahon D, Thakur BB. A study on serum prolactin level and its relationship with thyroid profile in infertile women. Indian J Basic Appl Med Res. 2017;7(1):5-11.

9. Hivre MD, Bhale DV, Mahat RK, Bujurge AA. Study of serum TSH and prolactin levels in patients of female infertility. Inter $\mathrm{J}$ Recent Trends Sci Technol. 2013;9(1):144-5.

10. Sharma P, Prasad S, Tangri N. Female infertility and its correlation with serum prolactin and $\mathrm{TSH}$ concentration: an unmatched case control study. J Pharm Biomed Sci. 2013;30(30):902-7.

11. Rahman D, Fatima P, Banu J. Thyroid disorders in female subfertility. JCMCTA. 2008;19(2):46-50.

12. Sharma UR, Parmar C. Thyroid profile in infertile women and menstrual dysfunction. Indian Med Gazette. 1998:1-7.

13. Joshi JV, Bhandarkar SD, Chadha M, Balaiah D, Shah R. Menstrual irregularities and lactation failure may precede thyroid dysfunction or goitre. J Postgraduate Med. 1993;39:137-41.

14. Koutras DA. Disturbances of menstruation in thyroid disease. Ann N Y Acad Sci. 1997;816:280-4.

15. Hendershot GE, Mosher WD, Pratt WF. Infertility and age: an unresolved issue. Fam Plann Perspect. 1982; 14:287.

16. Koutras DA. Disturbances of menstruation in thyroid disease. Ann N Y Acad Sci. 1997;816:280-4.

17. Cramer DW, Sluss PM, Powers RD, McShane P, Ginsburgs ES, Hornstein MD et al. Serum prolactin and TSH in an invitro fertilization population: is there a link between fertilization and thyroid function? J Assist Reprod Genet. 2003;20(6):210-5.

18. Bohnet HG, Fiedler K, Leidenberger FA. Subclinical hypothyroidism and infertility. Lancet. 1981;2:1278.

19. Trokoudes KM, Skordis N, Picolos MK. Infertility and thyroid disorders. Curr Opin Obstet Gynecol. 2006; 18:446-51.

20. Bispink L, Brandle W, Lindner C, Bettendorf G. Preclinical hypothyroidism and disorders of ovarian function. Geburtshilfe Frauenheilkd. 1989;49:881-8.

21. Raber W, Nowotny P, Vytiska-Binstorfer E, Vierhapper $H$. Thyroxine treatment modified in infertile women according to thyroxine-releasing hormone testing: 5-year follow-up of 283 women referred after exclusion of absolute causes of infertility. Hum Reprod. 2003;18:707-14.

Cite this article as: Keerthanaa SR, Hiremath PB. Analytical study of thyroid and prolactin hormone levels in infertile women with menstrual irregularities. Int J Reprod Contracept Obstet Gynecol 2020;9:1328-34. 